\title{
The relationship between social support and quality of life in iranian clients
}

\section{with cancer}

Torkmandi $\mathrm{H}^{1}$, Heidaranlu $\mathrm{E}^{2}$, Firouzbakht $\mathrm{M}^{3}$, Tahmasbi $\mathrm{B}^{4}$, Ziyari $\mathrm{M}^{5}$, Yaghoobzadeh $\mathrm{A}^{6}$,

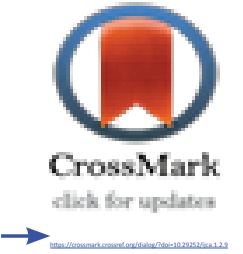
Goudarzian A.M ${ }^{7}$, Sharifnia S.H ${ }^{8}$, Mohammadinezhad M $^{9^{*}}$

1- Department of Operation Room, Faculty of Paramedicine, Alborz University of Medical Science, Karaj, Iran.

2- Assistant Professor of Baqiyatallah University of Medical Science, Trauma Research Center, Nursing Faculty, Baqiyatallah University of Medical Sciences, Tehran, Iran.

3- PhD Candidate ,Health Research Institute, Babol University of Medical Sciences. Mazandaran. Iran.

4- Assistant Professor, Amol School of Nursing and Midwifery, Mazandaran University of Medical Sciences, Sari, Iran.

5- MSc of Nursing, Student of Research Committee, Tehran University of Medical Sciences, Tehran, Iran.

6- PhD Student in Nursing, School of Nursing and Midwifery, Tehran University of Medical Science, Tehran, Iran.

7- MSc of Nursing, Student of Research Committee, Mazandaran University of Medical Sciences, Tehran, Iran.

8- PhD of Nursing, Assistant Professor, School of Nursing and Midwifery Amol, Mazandaran University of Medical Sciences, Sari, Iran.

9- MSc of Nursing, Sudent Research Committee, Iran University of Medical Sciences, Tehran, Iran.

Corresponding Author: Mohammadinezhad M, MSc of Nursing, Sudent Research Committee, Iran University of Medical Sciences, Tehran, Iran.

Email: mobinmohammadinejad@gmail.com

Received: 1 March $2019 \quad$ Accepted:13 May 2019

\section{Abstract}

Introduction: Regarding the prevalence and incidence of cancer has been increased, it is important to conduct studies that are better suited to this chronic and stressful disease. The present study aimed to investigate the relationship between social support and quality of life in cancer patients.

Method: A simple random sampling method was used in this descriptive- sectional study that was conducted in 2018. Data were collected using demographic questionnaire, FACT_G for assessing quality of life questionnaire and MPSS questionnaire in order to measure social support.

Results: The mean and standard deviation of the patients presented in the study was $49.65 \pm 14.93$.

The results showed that social support had a significant relationship with physical $(\mathrm{B}=-0.16)$, psychological $(\mathrm{B}=-0.13)$, social $(\mathrm{B}=0.29)$ and functional dimensions $(\mathrm{B}=0.21)$ of quality of life. Conclusion: Patients need the support of healthcare system, family, and their relatives. Social support provided by family and friends is an important factor in influencing the quality of life of cancer patients. As a result, this process will make the cancer patients better adapted.

Key Words: Social support, Quality of Life, Cancer.

\begin{tabular}{|l|l|}
\hline \multicolumn{3}{|c|}{ Access this article online } \\
\hline
\end{tabular}




\section{بررسى ارتباط بين حمايت اجتماعى و كيفيت زندكى در افراد مبتلابه سرطان ايرانى}

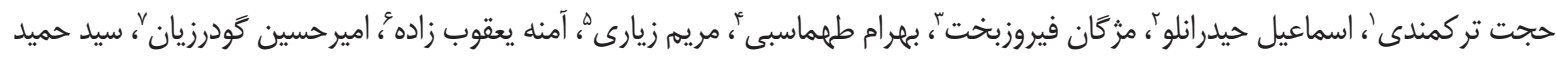

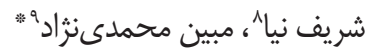

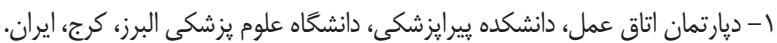

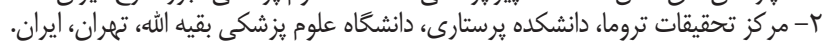

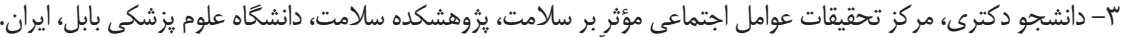

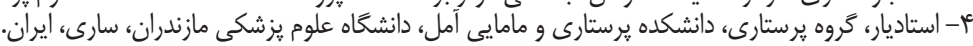

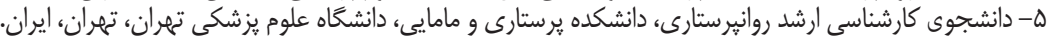

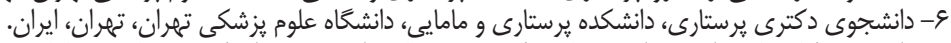

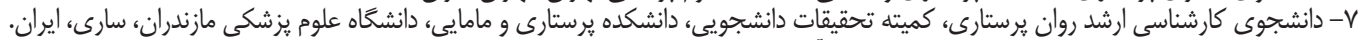

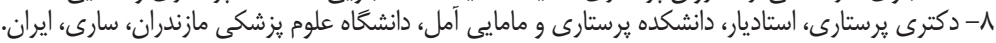

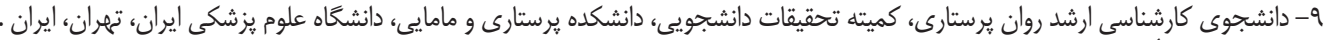

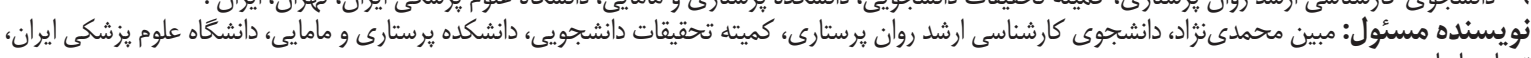

ايميل: ايران:. mobinmohammadinejad@gmail.com تاريخ بذيرش:

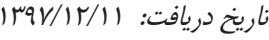

مقدمه: با توجه به اينكه در جامعه ايران ميزان شيوع و بروز سرطان افزايش يبيداكرده است، لزوم انجام مطالعاتى كه باعث ساز كارى بهتر با اين بيمارى

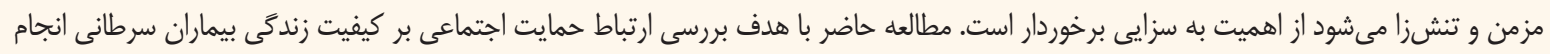
شده است.

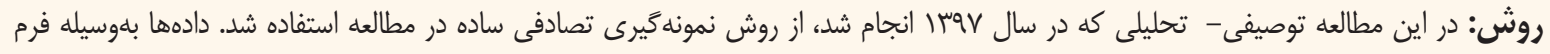

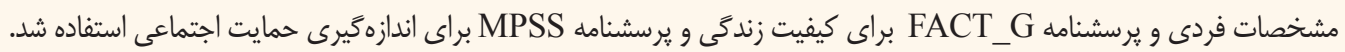

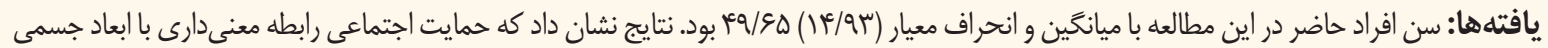

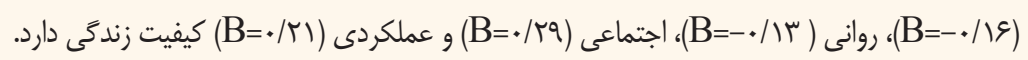

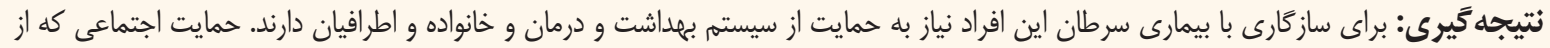

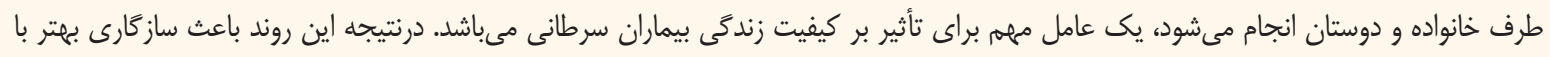
بيمارى سرطان مىشود.

مقابل متأسفانه عوارض سرطان مى توانند باعث كاهش كيفيت مقدمه

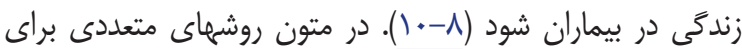

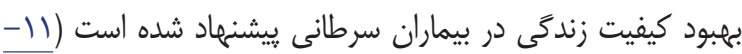

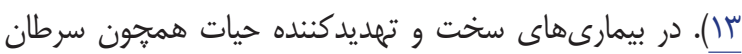

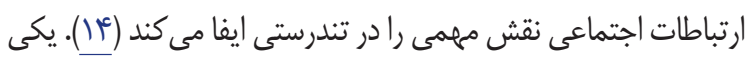

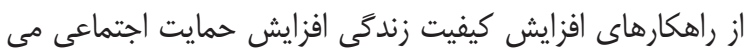

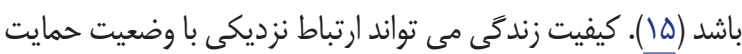

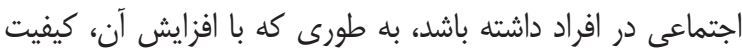

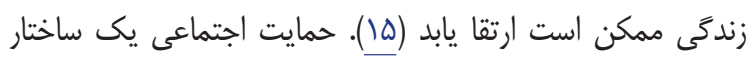

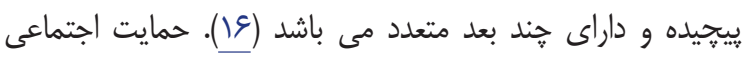

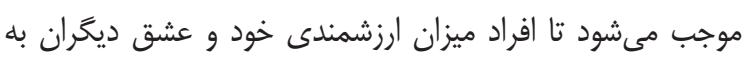

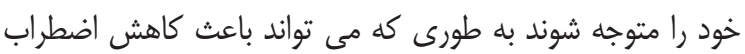

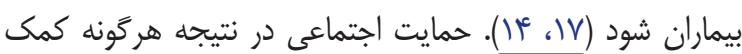

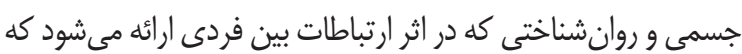

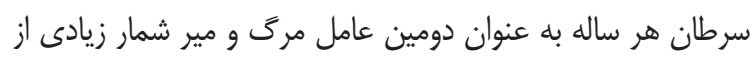

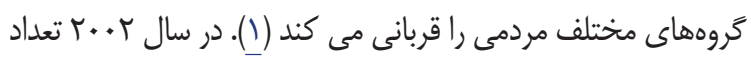

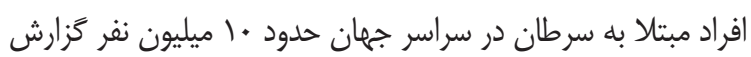

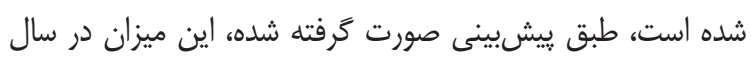

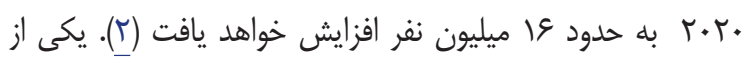

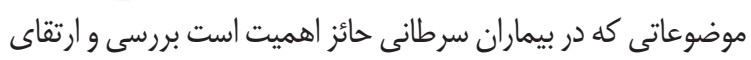

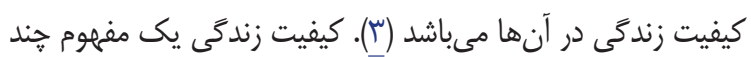

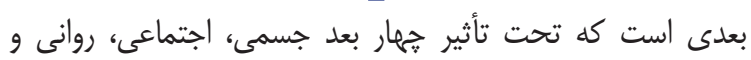

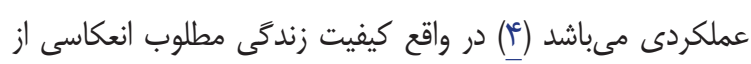

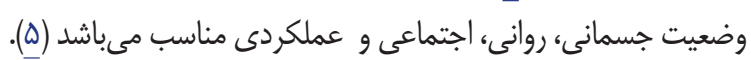

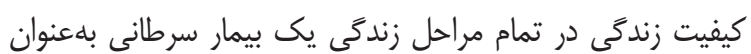

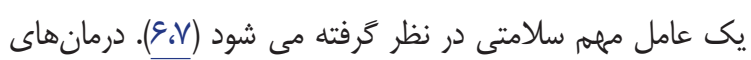

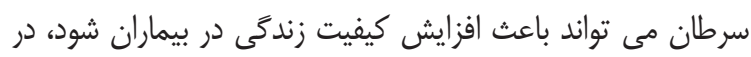


از مقياس Multidimensional Scale of Perceived Social

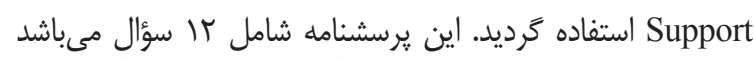

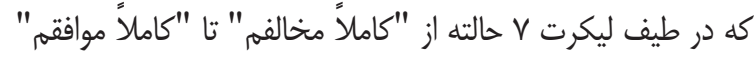

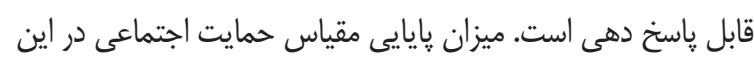

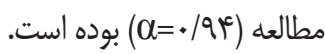
در ابتدا بيماران در خصوص اهداف و مراحل مطالعه مطلع شدند.

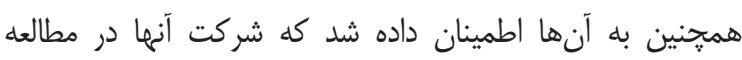
داوطلبانه است. تمامى اطالاعات بيماران با تخصيص به كد به به هر بيمار، غير قابل شناسايى گرديد. تجزيه و تحليل داده

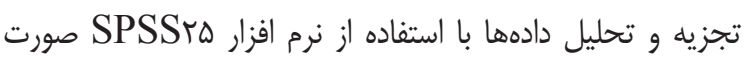

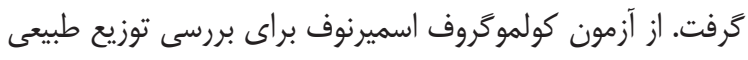

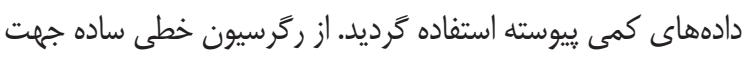
ييشيينى متغيرهاى ييشبينى كننده سطح كيفيت زندگى افراد

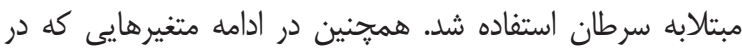

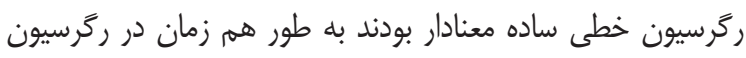

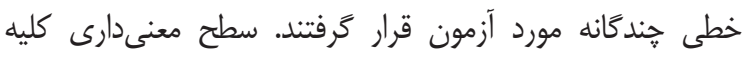

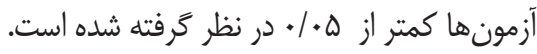

ملاحظات اخلاقى

مطالعه حاضر توسط كميته اخلاق دانشگًاه علوم يزشكى مازندران

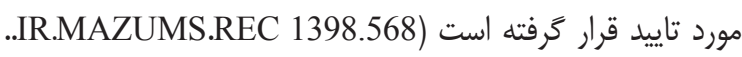
در ابتدا بيماران در خصوص اهداف و مراحل مطالعه مطلع شدند.

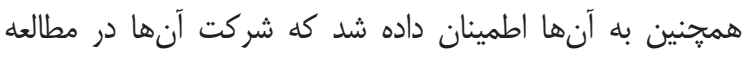
داوطلبانه است. تمامى اطلاعات بيماران با تخصيص كد به به هر بيمار، غيرقابلشناسايى گر ديد.

يافته ها

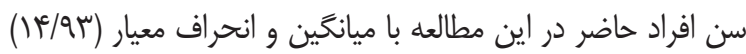

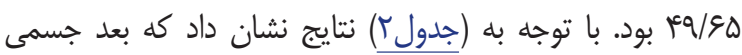

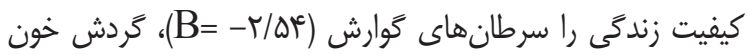
(B= r//9)

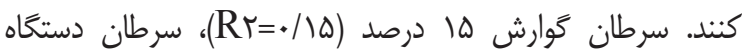

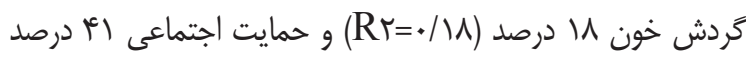

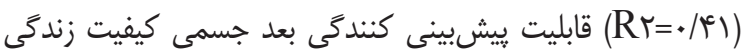

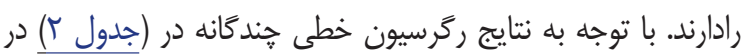

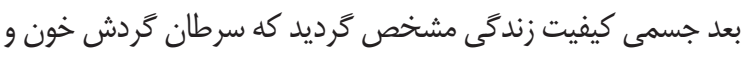

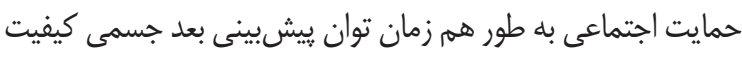

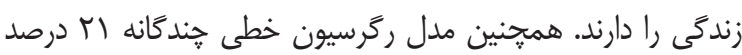

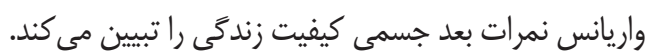

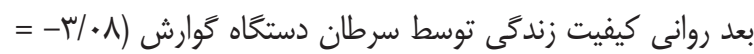
B
קنين حمايتهايى موجب كاهش استرسهاى روانشناختى و افكار

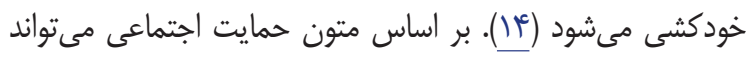

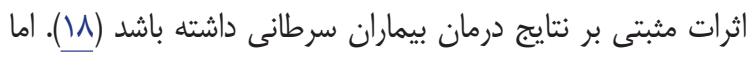

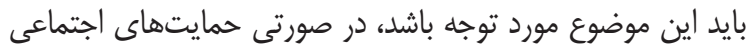

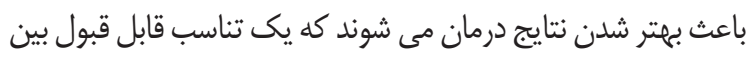

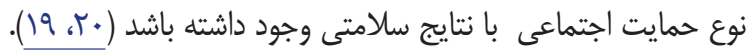

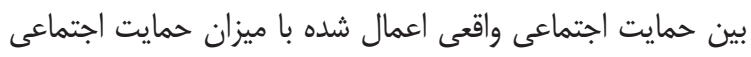

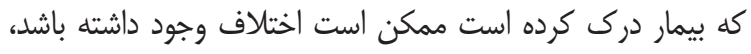

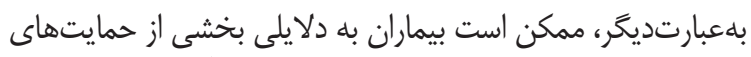

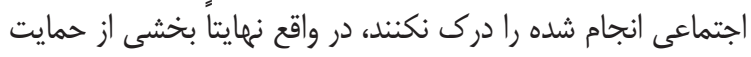

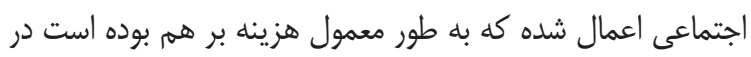

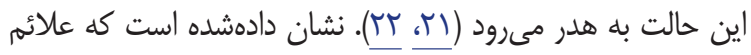

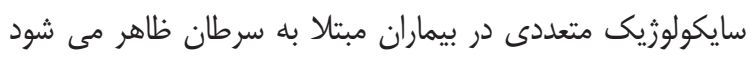

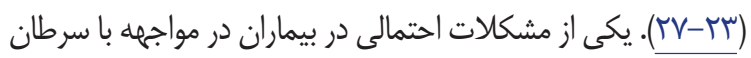

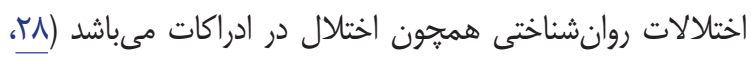

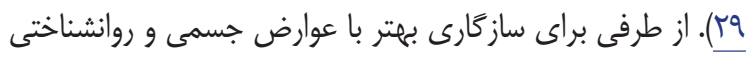

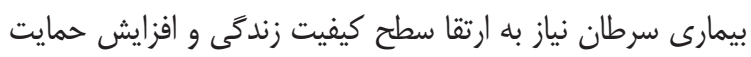

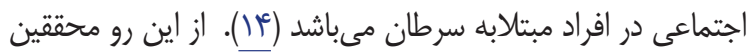

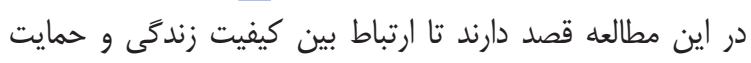
اجتماعى را در افراد مبتلابه سرطان را بررسى نمايند.

روش مطالعه

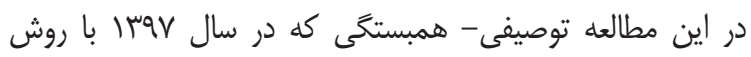

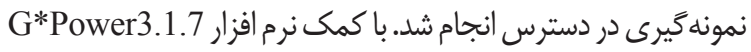

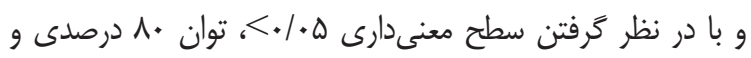

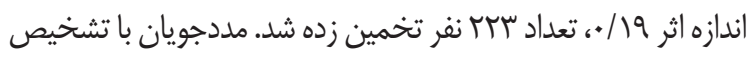

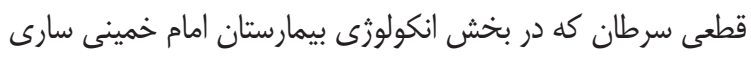

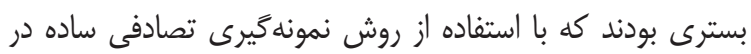

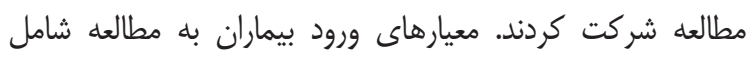

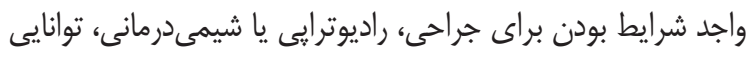

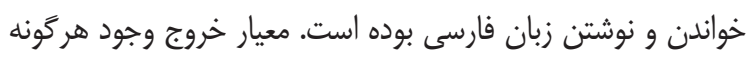

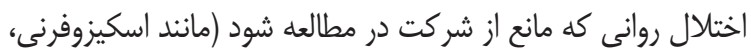

$$
\text { دمانس و افسردگى شديد) بود. }
$$

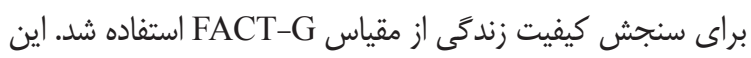

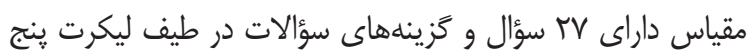

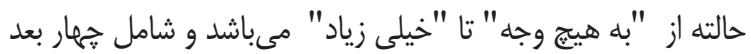

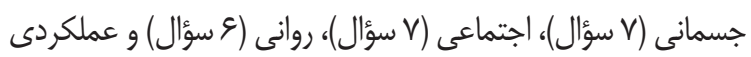

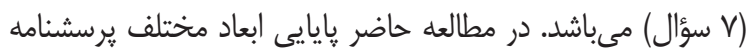

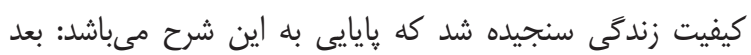

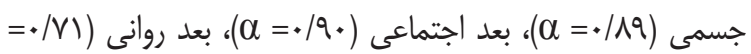

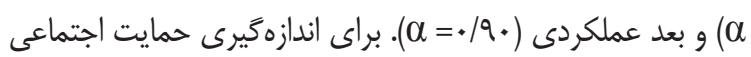


علاوه بر اين متغير حمايت اجتماعى توان ييشيبنى بعد عملكردى

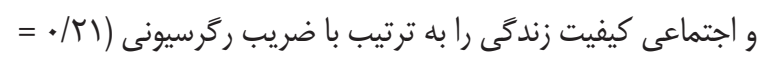
B

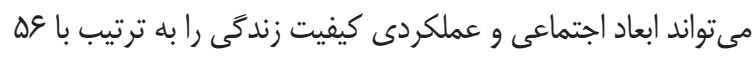

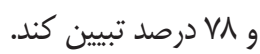

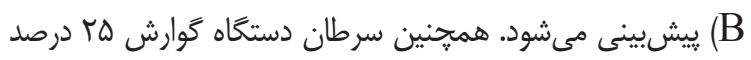

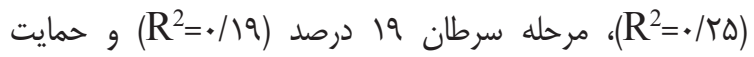

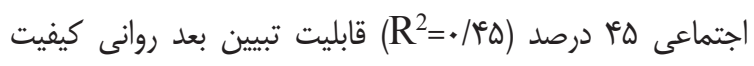

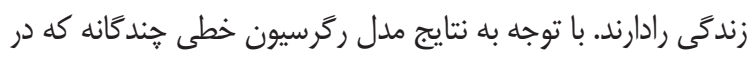

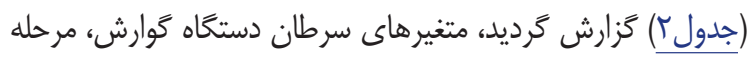

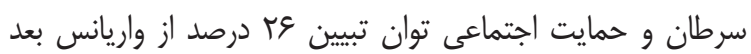
روانى كيفيت زندگى را دارد.

جدول (: مشخصات دموكر افيك افراد حاضر در مطالعه

\begin{tabular}{|c|c|c|c|}
\hline فرأرانى & فراوانى & متغير & \\
\hline $\begin{array}{l}r \mid / 1 \\
1 N / \Lambda \\
11 / \mu \\
0 / \Lambda\end{array}$ & 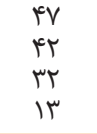 & مرحله| مرحله & مرحله سرطان \\
\hline $\begin{array}{l}\Delta \cdot / f \\
\mathrm{rq} / \mathrm{q}\end{array}$ & $\begin{array}{l}1 \cdot V \\
1 \cdot 0\end{array}$ & زرد & جنسيت \\
\hline $\begin{array}{l}V / 1 \\
1 \% / 1 \\
1 \% / 1\end{array}$ & سצ" & متأهل مجرد & وضعيت تأهل \\
\hline $\begin{array}{l}T Q / 1 \\
r N / F \\
r N / \mathcal{F} \\
r V / \Lambda\end{array}$ & $\begin{array}{l}\text { rQ } \\
\text { rQ } \\
\text { rF } \\
\text { rF }\end{array}$ & 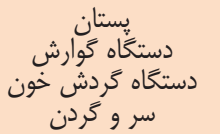 & نوع سرطان \\
\hline
\end{tabular}

جدول r: نتايج ركرسيون خطى ساده و ركرسيون خطى جندكانه

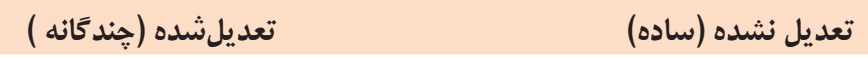

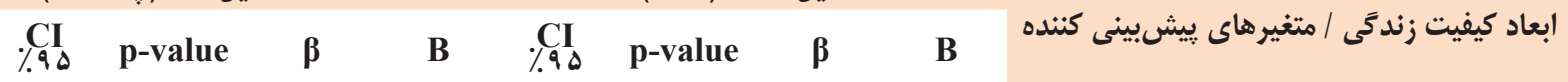

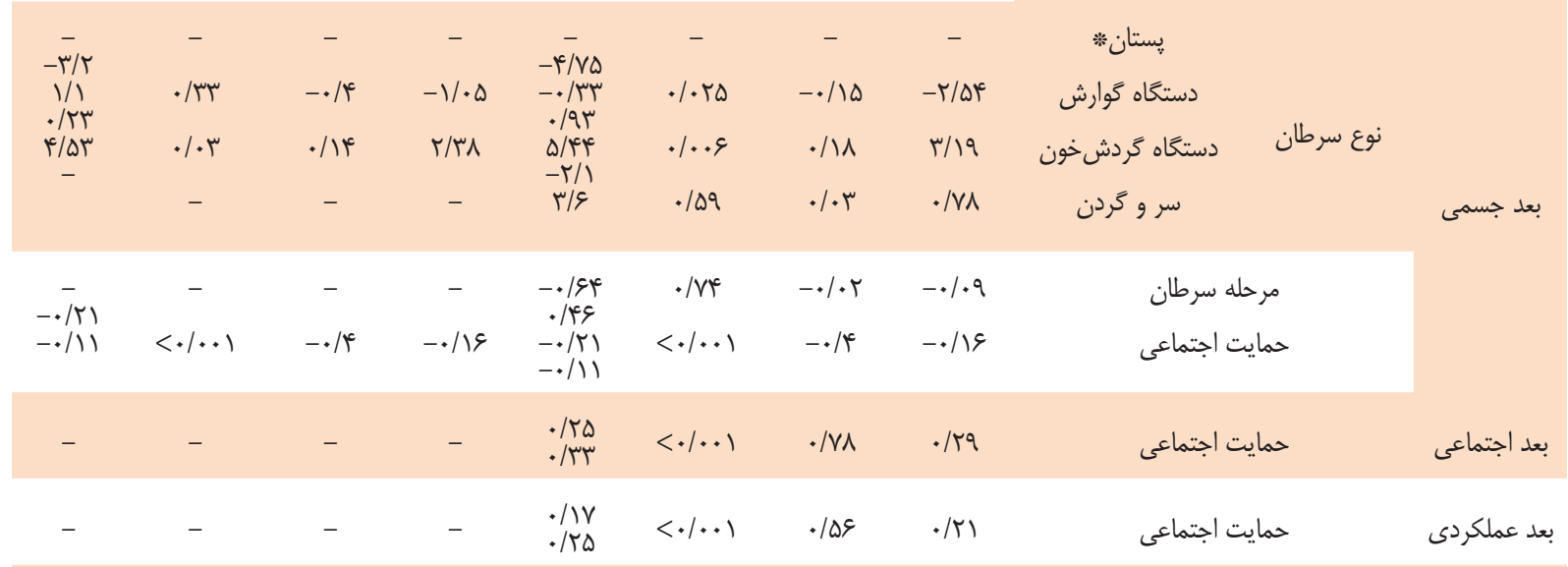

\begin{tabular}{|c|c|c|c|c|c|c|c|c|c|}
\hline - & - & - & - & 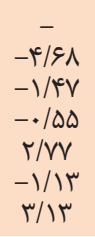 & $\begin{array}{c}- \\
<\cdot / . \cdot 1 \\
. / 19 \\
. / 1 \omega\end{array}$ & $\begin{array}{c}- \\
-\cdot / r \Delta \\
\cdot / \cdot 1 \\
. / \cdot 9\end{array}$ & $\begin{array}{c}1 \\
-r / \cdot 1 \\
1 / 1 \\
1\end{array}$ & 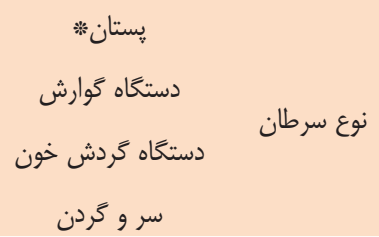 & ازاز \\
\hline $\begin{array}{l}-\cdot / V \Lambda \\
-\cdot / \cdot V\end{array}$ & $.1 \cdot 11$ &.$- / 14$ & $\begin{array}{c}-/ F T \\
-\end{array}$ & $\begin{array}{l}-\cdot / 91 \\
-\cdot / r\end{array}$ & . & -.119 & -.109 & مرحله سرطان & \\
\hline $\begin{array}{l}-\cdot / 10 \\
-\cdot 1 \cdot 1\end{array}$ & $<\cdot / \cdot \bullet \mid$ &.$- / / q q$ &.$- / 11$ & $\begin{array}{l}-. / 19 \\
-.1 .9\end{array}$ & $<\cdot / \cdot+1$ &.$- / 4 \Delta$ & س & حمايت اجتماعى & \\
\hline
\end{tabular}


نتايج مطالعه حاضر در ارتباط بين حمايت اجتماعى با بعد عملكردى و

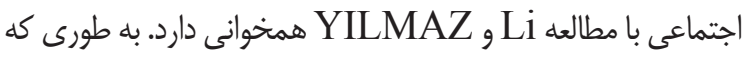

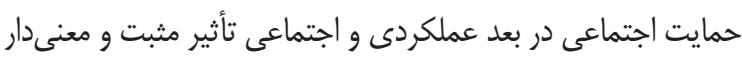

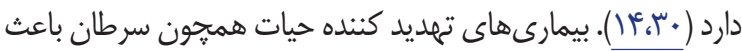
كاهش كيفيت زندگى اين افراد مىشود و همجنين بيماران سرطانى با فشارهاى متعدد روانشناختى مواجه هستند كه بر سطح عملكرد و روابط اجتماعى اين بيماران اثر منفى مى كذارد. اين عوامل باعث طولانى شدن روند سازكًارى با بيمارى سرطان مى شود. در اين حالت

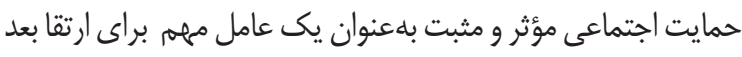

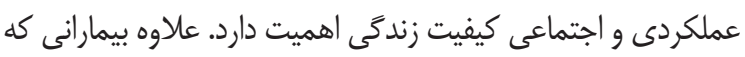

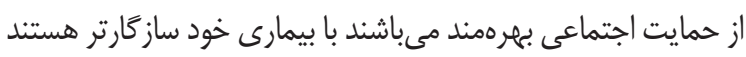
و سطح عملكرد و روابط اجتماعى آن ها بيشتر مى باشد (•مّ). درنتيجه در جامعه ايران با توجه حمايت اجتماعى از طرف اعضاى خانواده و

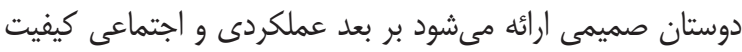

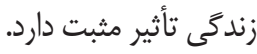

\section{نتيجه كيرى}

بيمار ان مبتلا به سرطان با تنشهاى مختلف جسمى و روانشناختى

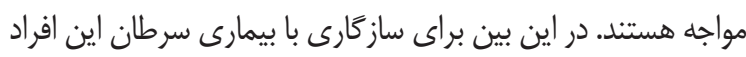
نياز به حمايت از سيستم بهداشت و درمان و خانواده و اطرافيان دارند. يكى از مهمترين حمايتهايى كه مىتواند درروند ساز كارى تأثير به سز ايیى بحذارد، حمايت اجتماعى مى باشد كه از طرف خانواده و دوستان اعمال مىشود. همخِنين حمايت اجتماعى بهعنوان يك متغير مستقل توان بيشيينى كيفيت زندگى اين بيماران را دارد. همان طور كه مىدانيم كيفيت زندگى يكى از مهمترين موضوعات براى

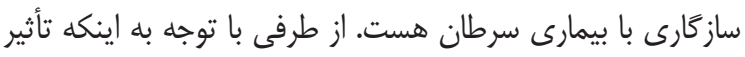
حمايت اجتماعى بر ابعاد كيفيت زندكى متفاوت بوده است نياز به مطالعات بيشترى در اين حوزه مىباشد.

از تمامى عزيزانى كه در انجام مطالعه حاضر به كَروه تحقيق كمى نمودند، بلخصوص كاركنان محترم مركز آموزشى درمانى بيمارستان امام خمينى (ره) سارى كه زير نظر دانشكاه علوم يزشكى و خدمات بهداشتى درمانى مازندران مىباشد، صميمانه تشكر مى شودد.
مطالعه باهدف تعيين ارتباط حمايت اجتماعى و كيفيت زندگى در بيماران سرطانى انجام شد. نتايج مطالعه نشان داد كه حمايت اجتماعى قدرت ييشينى كيفيت زندگى را دارد و همجنين حمايت اجتماعى به عنوان متغير مستقل ابعاد جسمى، اجتماعى، روانشناختى و روانى كيفيت زندگى را ييشيينى مى كند.

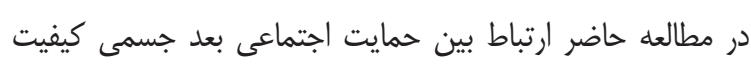
زندگى به صورت معكوس بوده است. به طورى كه افزايش حمايت اجتماعى موجب كاهش بعد جسمى كيفيت زندگى مىشود كه با

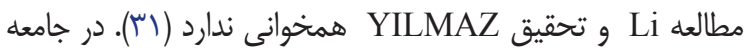
ايرانى مهمترين حمايتهاى اجتماعى از طرف خانواده و دوستان به افراد ارائه مىشود. با توجه به اينكه بيمارى سرطان باعث ايجاد مشكلات جسمى مى شود و همينين انجام درمانهاى جراحى باعث نقص در وضعيت جسمى اين افراد مى شود، اطرافيان و دوستان

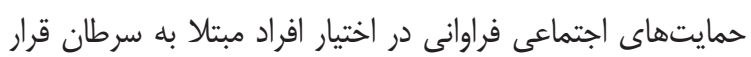
مىدهند. اين حمايتها باعث كاهش فعاليت فيزيكى روزانه و اختلال در انجام كارهاى مستقل روزانه مىشود. علاوه در بيمارانى كه به دليل سرطان محدوديت يا كاهش فعاليت فيزيكى دارند نيز حمايت اجتماعى دريافتى بالا است (؟َ). به همين دليل در جامعه ايرانى هر جه حمايت اجتماعى بيشتر شود بعد جسمانى كيفيت زندگى كاهش اله

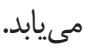
رابطه حمايت اجتماعى با بعد روانى كيفيت زندكَى نيز معكوس بوده

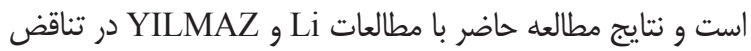

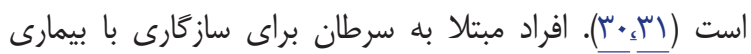

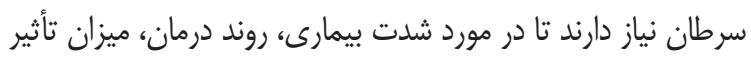

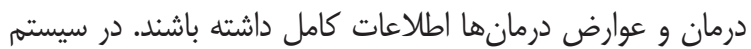
بهداشت و درمان ايران به اين مقولهها توجه كافى وجود ندارد و بيماران سرطانى هميشه با يك احساس مبرهم و يك سرى نيازهاى

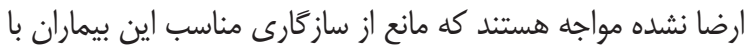

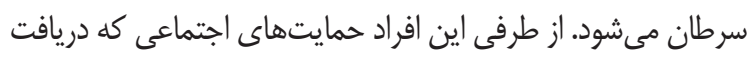

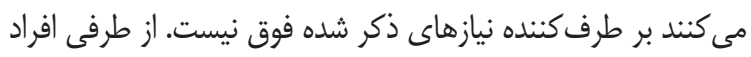

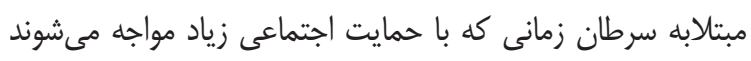
احساس تابو شدن بر آنها غالب مى كردد (سب). در نتيجه هر خها خها براى بيماران سرطانى جامعه ايران حمايت اجتماعى از طرف خانواده و دوستان بيشتر شود، بعد روانى كيفيت زندكى كمتر مىشود. 


\section{References}

1. Habek D, Habek JČ, Galić J, Goll-Barić SJAog, obstetrics. Acute abdomen as first symptom of acute leukemia. 2004; 270 (2):122-3.

2. Siegel R, DeSantis C, Jemal AJCacjfc. Colorectal cancer statistics, 2014. 2014; 64 (2): 104-17.

3. Claassens L, Van Meerbeeck J, Coens C, Quinten C, Ghislain I, Sloan EK, et al. Health-related quality of life in non-small-cell lung cancer: An update of a systematic review on methodologic issues in randomized controlled trials. 2011; 29 (15): 2104.

4. Luszczynska A, Pawlowska I, Cieslak R, Knoll N, Scholz U. Social support and quality of life among lung cancer patients: a systematic review. Psycho-Oncology. 2013; 22 (10): 2160-8.

5. Cocks K, King MT, Velikova G, Fayers PM, Brown JMJEjoc. Quality, interpretation and presentation of European Organisation for Research and Treatment of Cancer quality of life questionnaire core 30 data in randomised controlled trials. 2008; 44 (13): 1793-8.

6. Cheng SY, Lai YH, Chen SC, Shun SC, Liao $\mathrm{YM}, \mathrm{Tu} \mathrm{SH}$, et al. Changes in quality of life among newly diagnosed breast cancer patients in Taiwan. 2012; 21 (1-2): 70-9.

7. Costa-Requena G, Rodríguez A, FernándezOrtega PJSJoCS. Longitudinal assessment of distress and quality of life in the early stages of breast cancer treatment. 2013; 27 (1): 77-83.

8. Decat CSA, deAraujo TCCF, Stiles JJPO. Distress levels in patients undergoing chemotherapy in Brazil. 2011; 20 (10): 1130-3.

9. Gogou P, Tsilika E, Parpa E, Kouvaris I, Damigos D, Balafouta M, et al. The impact of radiotherapy on symptoms, anxiety and QoL in patients with cancer. 2015; 35 (3): 1771-5.

10. Gho SA, Steele JR, Jones SC, Munro BJJCC, Control. Self-reported side effects of breast cancer treatment: a cross-sectional study of incidence, associations, and the influence of exercise. 2013; 24 (3): 517-28.

11. Badr H, Krebs PJPO. A systematic review and meta-analysis of psychosocial interventions for couples coping with cancer. 2013; 22 (8): 1688704.

12. Preyde M, Synnott EJJoe-bsw. Psychosocial intervention for adults with cancer: a metaanalysis. 2009; 6 (4): 321-47.
13. De la Torre-Luque A, Gambara H, López E, Cruzado JAJIJoC, Psychology H. Psychological treatments to improve quality of life in cancer contexts: A meta-analysis. 2016; 16 (2): 211-9.

14. Yilmaz MS, PIYAL B, Akdur R. Social support and quality of life in a group of cancer patients (Ankara, Turkey). Turkish journal of medical sciences. 2017; 47 (3): 732-7.

15. Konecny LM, editor Quality of life, social support, and uncertainty among Latina breast cancer survivors. Oncology nursing forum; 2008: Oncology Nursing Society.

16. Uchino BN. Social support and physical health: Understanding the health consequences of relationships: Yale University Press; 2004.

17. Cantwell J, Muldoon OT, Gallagher SJRidd. Social support and mastery influence the association between stress and poor physical health in parents caring for children with developmental disabilities. 2014; 35 (9): 221523.

18. Dunn J, Occhipinti S, Campbell A, Ferguson M, Chambers SKJJoHP. Benefit finding after cancer: The role of optimism, intrusive thinking and social environment. 2011; 16 (1): 169-77.

19. Cohen S, Wills TAJPb. Stress, social support, and the buffering hypothesis. 1985; 98 (2): 310.

20. Kaniasty K, Norris FHJAJoCP. Social support and victims of crime: Matching event, support, and outcome. 1992; 20 (2): 211-41.

21. Haber MG, Cohen JL, Lucas T, Baltes BBJAjocp. The relationship between self-reported received and perceived social support: A meta-analytic review. 2007;39 (1-2):133-44.

22. Schwarzer R, Knoll N, Rieckmann NJHp. Social support. 2004; 158:181.

23. Dunn LB, Cooper BA, Neuhaus J, West C, Paul $\mathrm{S}$, Aouizerat B, et al. Identification of distinct depressive symptom trajectories in women following surgery for breast cancer. 2011; 30 (6): 683.

24. Langer S, Abrams J, Syrjala KJPOJotP, Social, Cancer BDo. Caregiver and patient marital satisfaction and affect following hematopoietic stem cell transplantation: a prospective, longitudinal investigation. 2003; 12 (3): 239-53.

25. Pitceathly C, Maguire PJEJoc. The psychological impact of cancer on patients' partners and other key relatives: a review. 2003; 39 (11):1517-24. 


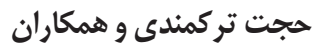

26. Kim Y, Duberstein PR, Sörensen S, Larson MRJP. Levels of depressive symptoms in spouses of people with lung cancer: effects of personality, social support, and caregiving burden. 2005; 46 (2):123-30.

27. Vanderwerker LC, Laff RE, Kadan-Lottick NS, McColl S, Prigerson HGJJocoojotASoCO. Psychiatric disorders and mental health service use among caregivers of advanced cancer patients. 2005; 23 (28): 6899.

28. Singer S, Das-Munshi J, Brähler EJAoO. Prevalence of mental health conditions in cancer patients in acute carea meta-analysis. 2009; 21 (5): 925-30.

29. Kissane DW, Grabsch B, Love A, Clarke DM, Bloch S, Smith GCJA, et al. Psychiatric disorder in women with early stage and advanced breast cancer: a comparative analysis. 2004; 38 (5): 320-6.

30. Li M-Y, Yang Y-L, Liu L, Wang L. Effects of social support, hope and resilience on quality of life among Chinese bladder cancer patients: a cross-sectional study. Health and quality of life outcomes. 2016; 14 (1):73.

31. Yilmaz MS, PIYYal B, Akdur R. Social support and quality of life in a group of cancer patients (Ankara, Turkey)*. TURKISH JOURNAL OF MEDICAL SCIENCES. 2017;47:732-7.

32. Faghani S, Rahmani A, Parizad N, Mohajjel-Aghdam A-R, Hassankhani H, Mohammadpoorasl A. Social support and its predictors among Iranian cancer survivors. Asian Pac J Cancer Prev. 2014; 15 (22): 9767-71.

33. Faghani S, Mohammadian R, Rahmani A, Mohajjel-Aghdam A-R, Hassankhani H, Azadi A. Supportive care needs of Iranian cancer survivors and relationships with social support. Asian Pac J Cancer Prev. 2015; 16 (15): 6339-45. 